\title{
Distribution of Cancer Cases Between January 01, 2014 and December 30, 2016 in Çorum City, Turkey
}

\author{
Yılmaz BAŞ, ${ }^{1}$ Behice Hande ERENLER, ${ }^{1}$ Güven GÜNEY, ${ }^{1}$ Ebru TURGAL, ${ }^{2}$ Havva Hande KESER, ${ }^{1}$ \\ Şahatayi ŞAHIN, ${ }^{3}$ İbrahim TUNUS ${ }^{4}$
}

'Department of Pathology, Hitit University, Faculty of Medicine, Çorum, Turkey

${ }^{2}$ Department of Biostatistics, Hitit University, Faculty of Medicine, Çorum, Turkey

${ }^{3}$ Department of Neurosurgery, Hitit University, Faculty of Medicine, Çorum, Turkey

${ }^{4}$ Department of Cancer, City Public Health Directorate, Çorum, Turkey

\section{OBJECTIVE}

This study aimed to investigate the frequency and distribution of adult cancer cases in Çorum city, Turkey.

\section{METHODS}

We retrospectively reviewed archive records and found 2204 cancer cases between January 01, 2014 and December 30, 2016 from the records of X University, Faculty of Medicine, Department of Pathology and City Public Health Directorate Cancer Department.

\section{RESULTS}

The mean age of the patients was 65.5 years. The male to female ratio was 1.40 , and $41.7 \%(n=919)$ of the patients were females and $58.3 \%(\mathrm{n}=1285)$ were males. The youngest patient was 18 years old and the oldest was 96 years old. The top ten cancers were skin ( $n=374,17.0 \%)$, lung $(n=205,9.3 \%)$, colorectal $(n=204$, $9.3 \%)$, breast $(\mathrm{n}=192,8.7 \%)$, prostate $(\mathrm{n}=174,7.9 \%)$, stomach $(\mathrm{n}=173,7.3 \%)$, urinary bladder $(\mathrm{n}=159$, $7.2 \%)$, thyroid $(\mathrm{n}=136,6.2 \%)$, uncertain primary $(\mathrm{n}=85,3.9 \%)$, and pancreatic $(\mathrm{n}=82,3.7 \%)$ cancers.

\section{CONCLUSION}

Development of cancer registry centers, upgrading to an active registry system, and obtaining all cancer data from health institutions and unifying it in a single organization are mandatory to achieve reliable data. Dissemination of screening methods is also important. As a result, determination of local cancer risk factors with the development of early diagnostic methods and the creation of cancer registration system will form the basis for future studies to be developed to prevent cancer.

Keywords: Cancer; Çorum city; Epidemiology.

Copyright $\odot$ 2017, Turkish Society for Radiation Oncology

\section{Introduction}

Cancer is the leading cause of death in both more and less economically developed countries; the burden of cancer is expected to increase worldwide because of the growth and aging of the population, particularly in less developed countries, in which approximately $82 \%$ of the world's population resides.[1] An estimated 14.1 million new cancer cases and 8.2 million cancer deaths occurred in 2012 worldwide[1,2]; 57\% (8 million) 


\begin{tabular}{|c|c|c|c|c|c|c|c|c|}
\hline \multirow[t]{2}{*}{ Rank } & \multirow[t]{2}{*}{ Localization } & \multicolumn{2}{|c|}{ Total } & \multicolumn{2}{|c|}{ Male } & \multicolumn{2}{|c|}{ Female } & \multirow[t]{2}{*}{$P$ value } \\
\hline & & $\mathbf{n}$ & $\%$ & $\mathbf{n}$ & $\%$ & $\mathbf{n}$ & $\%$ & \\
\hline 1 & Skin (C44) & 374 & 17.0 & 210 & 16.3 & 164 & 17.5 & 0.000 \\
\hline 2 & Lungs (C33-34) & 205 & 9.3 & 168 & 13.1 & 37 & 4.0 & \\
\hline 3 & Colorectal (C18-21) & 204 & 9.3 & 124 & 9.6 & 80 & 8.7 & \\
\hline 4 & Breast (C50) & 192 & 8.7 & & & 192 & 20.9 & \\
\hline 5 & Prostate (C61) & 174 & 7.9 & 174 & 13.5 & & & \\
\hline 6 & Stomach (C16) & 173 & 7.9 & 119 & 9.3 & 54 & 5.9 & \\
\hline 7 & Urinary bladder (C67) & 159 & 7.2 & 136 & 10.6 & 23 & 2.5 & \\
\hline 8 & Thyroid (C73) & 136 & 6.2 & 28 & 2.2 & 108 & 11.8 & \\
\hline 9 & Primer uncertain $(C 26,39,48,76-80)$ & 85 & 3.9 & 53 & 4.1 & 32 & 3.5 & \\
\hline 10 & Pancreas (C25) & 82 & 3.7 & 49 & 3.8 & 33 & 3.6 & \\
\hline 11 & Non Hodgkin lymphoma (C82-85) & 59 & 2.7 & 39 & 3.0 & 20 & 2.2 & \\
\hline 12 & Corpus uteri (C54) & 51 & 2.3 & & & 51 & 5.5 & \\
\hline 13 & Hematopoietic (C90-96) & 43 & 2.0 & 34 & 2.6 & 9 & 1.0 & \\
\hline 14 & Hepatocellular carcinoma (C22) & 29 & 1.3 & 16 & 1.2 & 13 & 1.4 & \\
\hline 15 & Kidney (C64-66) & 27 & 1.2 & 18 & 1.4 & 9 & 1.0 & \\
\hline 16 & Lip, oral cavity (C00-08) & 25 & 1.1 & 17 & 1.3 & 8 & 0.9 & \\
\hline 17 & Brain (C70-72) & 24 & 1.1 & 14 & 1.1 & 10 & 1.1 & \\
\hline 18 & Ovary (C56) & 20 & 0.9 & & & 20 & 2.2 & \\
\hline 19 & Cervix uteri (C53) & 16 & 0.7 & & & 16 & 1.7 & \\
\hline 20 & Periton C48/plevra C38.4-C78.2/perikard (C45.2) & 15 & 0.7 & 8 & 0.6 & 7 & 0.8 & \\
\hline 21 & Esophagus (C15) & 14 & 0.6 & 11 & 0.9 & 3 & 0.3 & \\
\hline 22 & Soft tissue (C47-49) & 14 & 0.6 & 9 & 0.7 & 5 & 0.5 & \\
\hline 23 & Kaposi sarcoma (C46) & 11 & 0.5 & 8 & 0.6 & 3 & 0.3 & \\
\hline 24 & Small intestine (C17) & 11 & 0.5 & 6 & 0.5 & 5 & 0.5 & \\
\hline 25 & Gallbladder (C23-24) & 10 & 0.5 & 6 & 0.5 & 4 & 0.4 & \\
\hline 26 & Hodgkin lymphoma (C81) & 10 & 0.5 & 7 & 0.5 & 3 & 0.3 & \\
\hline 27 & Larynx (C32) & 9 & 0.4 & 8 & 0.6 & 1 & 0.1 & \\
\hline 28 & Testis (C62) & 8 & 0.4 & 8 & 0.6 & & & \\
\hline 29 & Melanoma of skin (C43) & 6 & 0.3 & 4 & 0.3 & 2 & 0.2 & \\
\hline 30 & Nasopharynx (C11) & 5 & 0.2 & 2 & 0.2 & 3 & 0.3 & \\
\hline 31 & Bone (C40-41) & 5 & 0.2 & 4 & 0.3 & 1 & 0.1 & \\
\hline 32 & Heart (C38) & 2 & 0.1 & 1 & 0.1 & 1 & 0.1 & \\
\hline 33 & Urethra (C68) & 1 & 0.05 & 1 & 0.1 & & & \\
\hline 34 & Adrenal gland (C74) & 1 & 0.05 & 1 & 0.1 & & & \\
\hline 35 & Glans penis (C60.1) & 1 & 0.05 & 1 & 0.1 & & & \\
\hline 36 & Omentum (C48.1) & 1 & 0.05 & & & 1 & 0.1 & \\
\hline 37 & Vulva (C51) & 1 & 0.05 & & & 1 & 0.1 & \\
\hline \multirow[t]{2}{*}{38} & Salivary gland (C07-08) & 1 & 0.05 & 1 & 0.1 & & & \\
\hline & Total & 2204 & & 1285 & & 919 & & \\
\hline
\end{tabular}

of new cancer cases and 65\% (5.3 million) of cancer deaths occurred in less developed countries.[3]

Although cancer control efforts seem to be obscure in the current global health agenda, in 2005, the World Health Organization (WHO) passed the Resolution on Cancer Control WHO 58.22, urging member states to conduct cancer control and prevention activities. "Cancer surveillance is the ongoing, timely, and systematic collection and analysis of information on new cancer cases, extent of disease, screening tests, treatment, sur- vival, and cancer deaths." Surveillance systems, including cancer registries, allow countries to obtain specific data by geographic region from people diagnosed with cancer and to use the data to develop preventive, diagnostic, or therapeutic practices; to assess the efficacy of these interventions and initiate research studies; and to develop policies and allocate funding.[4] The increase in cancer incidence and mortality in Turkey has led the Turkish Ministry of Health (Türkiye Cumhuriyeti Sağlık Bakanlığı-TCSB) to establish Cancer Early 
Table 2 Distribution of cases based on gender and age group $(n=2204)$

\begin{tabular}{|c|c|c|c|c|}
\hline Age group (years) & Total number, n (\%) & \pm Males, n (\%) & 土Females, n (\%) & $P$ value* \\
\hline 18-19 & $6(0.3)$ & $1(0.1)$ & $5(0.5)$ & 0.000 \\
\hline $20-29$ & $42(1.9)$ & $17(1.3)$ & $25(2.7)$ & \\
\hline $30-39$ & $83(3.8)$ & $32(2.5)$ & $51(5.5)$ & \\
\hline $40-49$ & $196(8.9)$ & $70(5.4)$ & $126(13.7)$ & \\
\hline $50-59$ & $374(17.0)$ & $207(16.1)$ & $167(18.2)$ & \\
\hline $60-69$ & $593(26.9)$ & $390(30.4)$ & $203(22.1)$ & \\
\hline 70-79 & $579(26.3)$ & $364(28.3)$ & $215(23.4)$ & \\
\hline $80-89$ & 300 (13.6) & $184(14.3)$ & $116(12.6)$ & \\
\hline $90-99$ & $31(1.4)$ & $20(1.6)$ & $11(1.2)$ & \\
\hline
\end{tabular}

Diagnosis, Screening, and Training Centers (Kanser Erken Tanı, Tarama ve Eğitim Merkezi-KETEM) in the last 10 years and aims to expand these centers both in number and distribution within the country, to create and initiate national screening programs, and to reestablish and modernize the already existing cancer diagnosis and treatment centers. The aim of this workshop, which was organized by TCSB, was to determine the incidence of cancer in Turkey.[5] Similarly, in this study, we aimed to determine the cancer distribution in provinces.

\section{Materials and Methods}

This is a retrospective descriptive study on organ/system distribution of cancer cases diagnosed in Çorum city, Turkey. Permission was granted from the ethics committee of X University Medical Faculty to review the pathology archive records of the Pathology Department and City Public Health Directorate Cancer Department.

Histopathological reports and cancer registry informations were included in data analysis if there was no suspicion about the diagnosis. The archive records were examined between January 01, 2014 and December 30, 2016 using a software that uses a specific database. Thus, a total of 98456 recorded pathology reports were retrospectively reviewed in the pathology department. If there was more than one biopsy of the same patient, the one that best represented the diagnosis was taken into consideration. If there were different biopsies of the same patient, these different biopsies were included in the study. Patients who had a diagnosis of metastatic cancer with a known primary source were excluded. Data from patients aged $<16$ years were also excluded. A total of 2204 cases in whom the diagnosis of cancer were made in Çorum city were recorded by gender, age, and system/organ and classified into the ten most frequent types of cancer both in general and in terms of gender distribution.

Statistical analysis was performed using SPSS version 21.[5] Categorical variables were analyzed using the chi-square or Fischer's exact test. Continuous variables were analyzed using the Student's t-test or Wilcoxon signed rank test depending on the variability of data. A P value of $<0.05$ was considered statistically significant. The two proportion z-test was used to compare two observed proportions.

\section{Results}

The male to female ratio was 1.40 , and $41.7 \%(\mathrm{n}=919)$ of the patients were females and $58.3 \%(n=1285)$ were males. The youngest patient was 18 years old and the oldest was 96 years old. The mean age of the patients was 65.5 years. In total, $327(14.8 \%)$ patients were aged $<50$ years and $1877(85.2 \%)$ were aged $>50$ years.

Distribution of all cancer cases in terms of organ, system, and gender is shown in Table 1.

Among the two gender groups, the top ten cancers were skin ( $\mathrm{n}=374,17.0 \%)$, lung $(\mathrm{n}=205,9.3 \%)$, colorectal $(\mathrm{n}=204,9.3 \%)$, breast $(\mathrm{n}=192,8.7 \%)$, prostate $(\mathrm{n}=174,7.9 \%)$, stomach $(\mathrm{n}=173,7.3 \%)$, urinary bladder $(\mathrm{n}=159,7.2 \%)$, thyroid $(\mathrm{n}=136,6.2 \%)$, uncertain primary $(n=85,3.9 \%)$, and pancreatic $(n=82,3.7 \%)$ cancers (Table 1).

Among females, the top 10 cancers were breast $(\mathrm{n}=192,20.9 \%)$, skin $(\mathrm{n}=164,17.5 \%)$, thyroid $(\mathrm{n}=108$, $11.8 \%)$, colorectal $(\mathrm{n}=80,8.7 \%)$, stomach $(\mathrm{n}=54,5.9 \%)$, corpus uteri $(\mathrm{n}=51,5.5 \%)$, lung $(\mathrm{n}=37,4.0 \%)$, pancreatic $(n=33,3.6 \%)$, primer uncertain $(n=32,3.5 \%)$, and urinary bladder $(\mathrm{n}=23,2.5 \%)$ cancers, whereas among males, the top 10 cancers were skin $(\mathrm{n}=210 \quad 16.3 \%)$, prostate $(\mathrm{n}=174,13.5 \%)$, lung $(\mathrm{n}=168,13.1 \%)$, urinary bladder $(n=136,10.6 \%)$, colorectal $(n=124,9.6 \%)$, stomach $(\mathrm{n}=119,9.3 \%)$, primer uncertain $(\mathrm{n}=53$, 


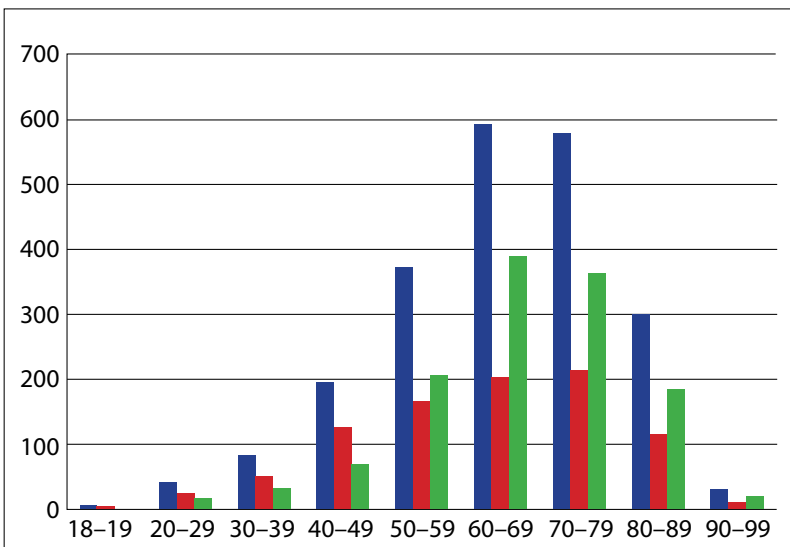

Fig. 1. Distribution of cancer cases according to age in 2014-2016.

$4.1 \%)$, pancreatic $(\mathrm{n}=49,3.8 \%)$, non-Hodkin lymphoma $(n=39,3.0 \%)$, and hematopoietic $(n=37,2.6 \%)$ cancers. Among 2204 cases with a diagnosis of cancer, $1285(58.3 \%)$ were males and 919 (41.7\%) were females. The frequency peaks between 60 and 69 years of age in males and females $(n=593,26.9 \%)$. Cancer most commonly occurred in 60-69 years of age in males $(n=390$, $30.4 \%)$, followed by $70-79$ years of age $(n=364,28.3 \%)$. In females, cancer most commonly occurred in 70-79 years of age $(n=215,23.4 \%)$, followed by $60-69$ years of age ( $n=203,16.0 \%$; Fig. 2 and 3). Among males and females, the highest incidence of cancer in our study, 593 $(26.9 \%)$, was seen in the age group of $60-69(\mathrm{P}<0.000)$ followed by the age group of $70-79$ years $(26.3 \%$; Tables 2 and Fig. 1). The least number of patients was in the age group of $18-19$ years $(0.3 \%)$.

Among males and females, the highest incidence of cancer, $374(17.0 \%)$, was in the skin $(\mathrm{P}<0.000)$, followed by lungs $(9.3 \%)$, colorectal $(9.3 \%)$, stomach (7.9\%), urinary bladder (7.2\%), and thyroid (Table 1$)$. The least incidence of cancer was in the heart $(0.3 \%)$.

Calculation of the $P$ value suggests the statistical significant association of cancer with gender and age group.

In females, breast cancer $(n=192,20.9 \%)$ was most commonly found and peaked in 50-59 years of age (Fig. 2).

In males, prostate carcinoma $(\mathrm{n}=174,13.5 \%)$ was the second most common cancer after skin cancer, and it peaked in 70-79 years of age (Fig. 3).

Between January 01, 2014 and December 30, 2016, $1576(71.5 \%)$ of these cancer patients were treated according to the data of the public health institution (Fig. 4) and 627 (28.5\%) patients died. In this study, we ex-

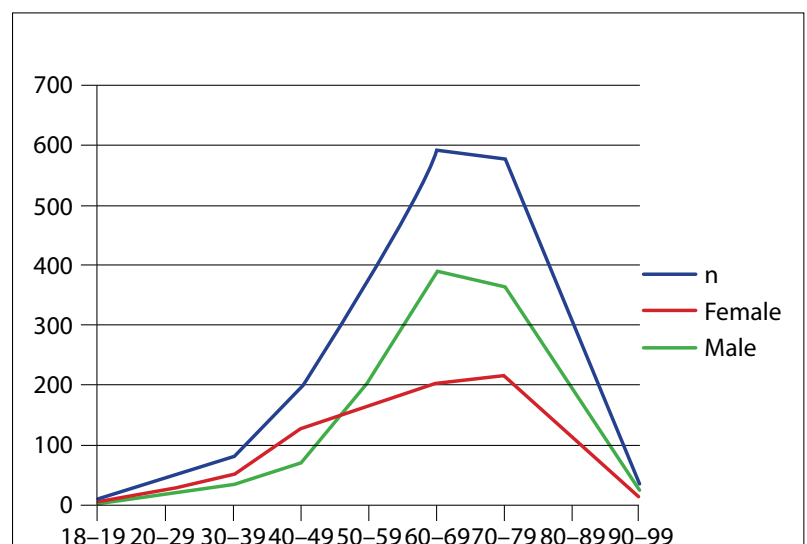

Fig. 2. Distribution according to gender and age.

amined the mortality rates only among the patients of Hitit University Education and Research Hospital, and age-specific (18-96 years) cancer mortality rate in Çorum city was $0.68 \%$ per 1000 in 2014, 0.38\% per 1000 in 2015 , and $0.59 \%$ per 1000 in 2016.

\section{Discussion}

Cancer registries set up throughout the country to collect and record data and report cancer cases in the areas they cover are the foundation of cancer surveillance activities.[4] However, it has been acknowledged that there is a "significant lack of relevant cancer data from developing countries." Registries require time, effort, expertise, and skills development so that they can become functional and meet international standards. [4] In addition, the establishment of cancer registry systems is of importance to reveal etiologic causes, necessary intervetions for cancer prevention, and for "cancer biology" studies to be developed and controlled.[6] When developed and developing countries are separately evaluated, it appears that the type and incidence rates of cancers vary. $[1,3]$

The five most common cancers (lung, breast, colorectal, prostate, and stomach) in both genders account for nearly half of all cancer cases. Lung and breast cancer are the most frequently diagnosed cancers and are the leading causes of cancer death in males and females, respectively, both overall and in less developed countries.[1,3]

In developed countries, lung and prostate cancers in males and breast and colorectal cancers in females are more frequent. On the other hand, in developing countries, lung, stomach, and liver cancer in males and 


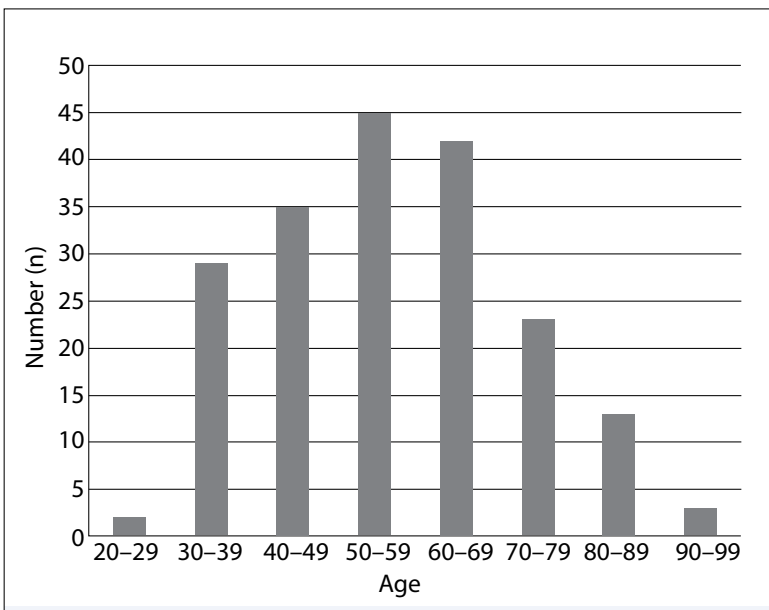

Fig. 3. Distribution of breast cancer cases according to age.

breast and cervical cancers in females are more frequent.[1,5]

In a study by Farley et al., lung cancer remains the most common cancer in the world, both in term of new cases ( 1.8 million cases, $12.9 \%$ of total) and deaths (1.6 million deaths, $19.4 \%$ ), because of the high mortality rate.[2] Breast cancer is the second most common cancer overall (1.7 million cases, $11.9 \%$ ) but is the fifth most common cause of death $(522,000,6.4 \%)$ because of its relatively favorable prognosis; these were followed, in terms of incidence, by colorectal cancer (1.4 million cases, 694,000 deaths), prostate cancer (1.1 million cases, 307,000 deaths), stomach cancer $(951,000$ cases, 723,000 deaths), and liver cancer $(782,000$ cases and 745,000 deaths).[4]

The first five most common cancer types in Turkey are similar to those in the world and other developed countries.[5] In our study, the first five most common cancers were skin $(n=374,17.0 \%)$, lung $(n=205,9.3 \%)$, colorectal $(n=204,9.3 \%)$, breast $(n=192,8.7 \%)$, and prostate $(\mathrm{n}=174,7.9 \%)$, respectively (Table 1$)$.

In Turkey, the age-adjusted cancer rates for males and females in 2012 were reported as $277.7 / 100,000$ and $188.2 / 100,000$, and there is a serious increase in

Table 3 Number and percentage of patients treated

\begin{tabular}{lc} 
Treatment methods and distribution ratio & $\mathbf{n}(\%)$ \\
\hline Surgery & $1176(53.4)$ \\
Radioterapy & $8(0.4 \%)$ \\
Chemotherapy & $376(17.1)$ \\
Therapy with hormone drugs & $5(0.2)$ \\
Other & $11(0.5)$ \\
Total & $1576(71.5)$ \\
\hline
\end{tabular}

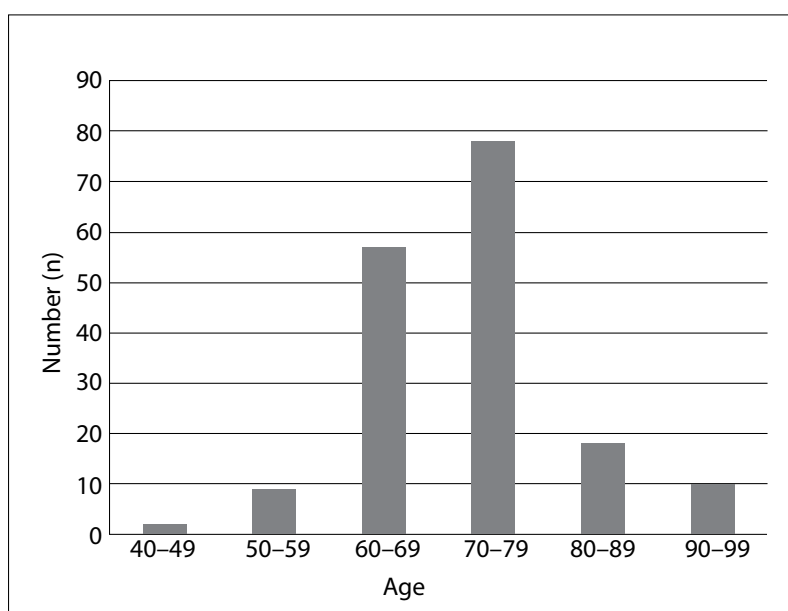

Fig. 4. Distribution of prostate cancer cases according to age.

the incidence and mortality rate of cancer.[5] In our study, age-specific (18-96 years) cancer mortality rate in Çorum city was $0.68 \%$ per 1000 in $2014,0.38 \%$ per 1000 in 2015, and $0.59 \%$ per 1000 in 2016. The most frequent age range in the study by Baş et al.[6] was 70-79 years, whereas in our study, it was 60-69 years. Similar to the study by Baş et al.[6], the female to male ratio in our study was 1.40 .

Lung cancer is the most common type of cancer in males in our country, which is directly related to tobacco use.[5] In our study, increase in lung cancer frequency is an important result. Because this result is different from that of a previous study by Baş et al. in the same city and unlike the previous study by Baş et al., it shows that fewer patients go to a different upper center.[6]

In Asia, colorectal cancer has the sixth highest cancer incidence and seventh highest cancer mortality for both genders (IARC, 2008).[7] In Turkey, it is the fourth most common cancer (6.9\% of total) in males and second in females (8.1\%).[8] As in the studies by Aykan et al.[8] and İzmirli et al.[9], colorectal cancer $(9.3 \%)$ was the third most common cancer according to our study.

One of the most common cancers is breast cancer, and it has a high incidence rate in all countries. The incidence rate of breast cancer ranges from 19.4 per 100,000 people in East Africa to 89.7 per 100,000 in West Europe.[10] Breast cancer in females (46.8/100 000) is the most common cancer in Turkey.[5] Screening programs are being implemented in KETEMs founded by TCSB, Universities, several hospitals, and private associations. [5] In our study, breast cancer was 
the most common cancer in females ( $\mathrm{n}=192,20.9 \%)$, similar to that reported in the studies by İzmirli et al.[9] (33.4\%) and Haydaroğlu et al.[11] (26.2\%). In Çorum city, given the preliminary diagnosis by USG, ease of mammography, and introduction of KETEM may have increased the number of breast cancer cases.

Prostate cancer is the third most common cancer in the world, and its geographical variability across the world is well-known. It has been reported as a rare disease in Asia and Africa (approximately four-seven per 100,000), whereas it is frequently diagnosed as an aging-related malignancy preferentially occurring in certain ethnic groups especially in the West (70-100 cases per 100,000 in Nordic European countries and North America).[12] According to the study by Zorlu et al., the overall age-adjusted incidence rate of prostate cancer was 35/100,000 in Turkey, with the highest rate identified in the city of Istanbul $(43.7 / 100,000)$ and the lowest rate in the city of Edirne (17.7/100,000). [12] As in the study by Baş et al.[6], in our study, prostate cancer $(14.9 \%)$ is the second most common cancer after skin cancer in males. However, the frequency of prostate cancer was found to be lower in the studies by İzmirli et al.[6] and Haydaroğlu et al.[9] In the study by Zorlu et al.[12], prostate cancer incidence rates was lower than $1 / 100,000$ in patients aged $<40$ years, whereas it was higher than $300 / 100,000$ in patients aged $>70$ years. Prostate cancer incidence rate was determined to be the highest between the ages of 75 and $79(386.7 / 100,000)$.[12] Similar to the study by Zorlu et al.[12], in our study, the prostate cancer incidence peaked in the age group of 70-79 years.

The incidence of thyroid malignancy has been increasing in Turkey for the past two decades. The increase in the frequency of thyroid cancer could be attributable to several different reasons in the case of Turkey: the Chernobyl nuclear accident, mandatory iodization for endemic iodine deficiency, increased diagnostic scrutiny, strict pathologic investigation, and changing surgical techniques.[13] In our study, thyroid cancer is the third most common cancer in females and 11 most common in males. This result is similar to that reported by Baş et al.[14] and İzmirli et al.[9] and is also consistent with the data of the Turkish Cancer Department (Türkiye Kanser Daire Başkanllğı). [15] In Turkey, the frequency of thyroid cancer has increased to $14 \%$ in females compared to last year.[15] It is known that radioactivity plays an important role as an etiological factor, especially in thyroid carcinomas. [16] In the Black Sea region of Turkey, thyroid cancer was at the 10th place until 1990, whereas it has moved to the first place in recent years. [16]

More than $70 \%$ of stomach cancer cases $(677,000$ cases) occur in developing countries (456,000 in males and 221,000 in females), and half the world total occurs in Eastern Asia (mainly in China).[2] Stomach cancer is the third leading cause of cancer death in both genders worldwide $(723,000$ deaths, $8.8 \%$ of the total). [2] In the study by Baş et al.[6], stomach cancer was at the 3rd place in both genders, whereas it is at the 6th place in this study. This decline is relative and can be explained by an increase in lung and breast cancer frequency.

Countries need to develop prevention and screening programs based on the frequency of the most common cancer. Cancer screening, early diagnosis, and effective treatment requires collaboration of several specialties in medicine. The aim of obtaining a successful result can only be achieved by the cooperation of all related medical divisions. Different clinics have to work together for cancer screening, early diagnosis, and effective treatment. A successful outcome can only be achieved through the cooperation of all relevant medical departments. The widespread deficiencies in population-based screening and effective treatment lead to an increase in delay in diagnosis and mortality. $[5,17]$ Overall average percentage of skin cancer $(\mathrm{p}<0.001)$, lung cancer $(\mathrm{p}=0.002)$, and breast cancer $(\mathrm{p}=0.009)$ in our study (in 2014-2017) is higher than that reported in the study by Baş et al.[14] (in 2008-2013) and is statistically significant.

Overall average percentage of colorectal cancer $(\mathrm{p}=0.458)$ and prostate cancer $(\mathrm{p}=0.574)$ in our study (in 2014-2017) is higher than that reported in the study by Baş et al. [6] (in 2008-2013) and is not statistically significant.

In conclusion, distribution of organ/system involvement in cancer cases that were diagnosed in Çorum city is not different from the data regarding Turkey in general. Development of cancer registry centers, upgrading to an active registry system, and obtaining all cancer data from health institutions unified in a single organization are mandatory to achieve reliable data. Serious and extensive research on the etiology is required. Dissemination of screening methods is also important. As a result, the determination of local cancer risk factors with the development of early diagnostic methods and creation of cancer registration system will form the basis for future studies to be developed for preventing cancer. This study suggests that the frequency of cancer increases with age and that early diagnosis methods have reached a sufficient level. 


\section{Disclosures Statement}

The authors declare no conflicts of interest.

Acknowledgments: The authors have no fundings or conflicts of interest to disclose.

Ethics Committee Approval: This study was conducted inaccordance with local ethical rules.

Peer-review: Externally peer-reviewed.

Conflict of Interest: None declared.

Authorship contributions: Concept - Y. B; Design - Y. B; Supervision - B. H. E; Materials - G. G, İ. T; Data collection \&/or processing - H. H. K; Analysis and/or interpretation Y. B; Literature search - Ş. Ş; Writing - Y. B; Critical review - B. H. E, G. G; Biostatistics - E. T.

\section{References}

1. Torre LA, Bray F, Siegel RL, Ferlay J, Lortet-Tieulent J, Jemal A. Global cancer statistics, 2012. CA Cancer J Clin 2015;65(2):87-108.

2. Ferlay J, Soerjomataram I, Dikshit R, Eser S, Mathers $\mathrm{C}$, Rebelo $\mathrm{M}$, et al. Cancer incidence and mortality worldwide: sources, methods and major patterns in GLOBOCAN 2012. Int J Cancer 2015;136(5):E35986.

3. Choi E, Lee S, Nhung BC, Suh M, Park B, Jun JK, et al. Cancer mortality-to-incidence ratio as an indicator of cancer management outcomes in Organization for Economic Cooperation and Development countries. Epidemiol Health 2017;39:e2017006.

4. Stillman FA, Kaufman MR, Kibria N, Eser S, Spires M, Pustu Y. Cancer registries in four provinces in Turkey: a case study. Global Health 2012;8:34.

5. Özmen V, Dağoğlu N, Dede İ, Akçakaya A, Kerem M, Göksel F, et al. Turkish Ministry of Health, 2nd Turkish Medical General Assembly Clinical Oncology Study Group Report. J Breast Health 2016;12(1):9-17.

6. Baş Y, Uzbay P, Güney G, Erenler BH, Yilmaz D, Ozdemir C. A study on distribution of cancer cases di- agnosed in Çorum. Turkish Journal of Pathology 2014;30(2):118-23.

7. Sunkara V, Hebert JR. The Colorectal Cancer Mortality-to-Incidence Ratio as a Potential Cancer Surveillance Measure in Asia. Asian Pac J Cancer Prev 2016;17(9):4323-6.

8. Aykan NF, Yalçın S, Turhal NS, Özdoğan M, Demir G, Özkan M, et al. Epidemiology of colorectal cancer in Turkey: A cross-sectional disease registry study (A Turkish Oncology Group trial). Turk J Gastroenterol 2015;26(2):145-53.

9. İzmirli M, Altın S, Olcum Dernek B, Ünsal M. Cancer statistics of SSK Okmeydanı Training and Research Hospitals Department of Oncology from 1999 to 2004. Turk J Oncol 2007;22(4):172-82.

10. Ghoncheh M, Pournamdar Z, Salehiniya H. Incidence and Mortality and Epidemiology of Breast Cancer in the World. Asian Pac J Cancer Prev 2016;17(S3):43-6.

11. Haydaroğlu A, Bölükbaşı Y, Özsaran Z. Analysis of cancer registration data in Ege University: evaluation of 34134 cases. Turk J Oncol 2007;22(1):22-8.

12. Zorlu F, Zorlu R, Divrik RT, Eser S, Yorukoglu K. Prostate cancer incidence in Turkey: an epidemiological study. Asian Pac J Cancer Prev 2014;15(21):9125-30.

13. Yildiz SY, Berkem H, Yuksel BC, Ozel H, Kendirci M, Hengirmen $\mathrm{S}$. The rising trend of papillary carcinoma in thyroidectomies: 14-years of experience in a referral center of Turkey. World J Surg Oncol 2014;12:34.

14. IBM Corp. Released 2012. IBM SPSS Statistics for Windows, Version 21.0. Armonk, NY:IBM Corp. Available at: http://www-01.ibm.com/support/docview. wss?uid=swg21476197. Accessed Dec 4, 2017.

15. Gultekin M, Boztas G, editors. Turkish Ministry of Health Public Health Agency Cancer Statistics; 2014. p. 9-19.

16. Karagöz F, Yıldız L, Barış S, Özdamar Ş, Bakırtaş M, Aydin O. 1991-1996 thyroid cancers statistics in the Ondokuz Mayıs University Faculty of Medicine. O.M.Ü Med J 1998;15(4):324-9.

17. Ferlay J, Autier P, Boniol M, Heanue M, Colombet M, Boyle P. Estimates of the cancer incidence and mortality in Europe in 2006. Ann Oncol 2007;18(3):581-92. 